\title{
Author Correction: Changes in mitochondrial homeostasis and redox status in astronauts following long stays in space
}

\author{
Hiroko P. Indo, Hideyuki J. Majima, Masahiro Terada, Shigeaki Suenaga, Kazuo Tomita, \\ Akira Higashibata, Noriaki Ishioka, Takuro Kanekura, Clare L. Hawkins, Michael J. Davies, \\ Daret K. St Clair \& Chiaki Mukai
}

Correction to: Scientific Reports https://doi.org/10.1038/srep39015, published online 16 December 2016

An institutional investigation at the JAXA Human Spaceflight Technology Directorate concluded that Ikuya Nonaka and Shin Yamada did not make contributions to writing the paper, analysing the data, or checking and confirming the contents of the paper. Ikuya Nonaka and Shin Yamada should not be listed as authors of the Article. The author list should read:

"Hiroko P. Indo, Hideyuki J. Majima, Masahiro Terada, Shigeaki Suenaga, Kazuo Tomita, Akira Higashibata, Noriaki Ishioka, Takuro Kanekura, Clare L. Hawkins, Michael J. Davies, Daret K. St Clair \& Chiaki Mukai”

The Author Contribution statement should read:

"H.P.I., S.S., K.T. and T.K. contributed to the whole analyses and discussion of the results. M.T., C.L.H., M.D., D.K.S. and H.J.M. contributed to the experimental planning and discussion of the results. A.H., N.I., C.M., contributed to all of these aspects in this study, including drafting the manuscript and executing the final revisions. All authors approved the final manuscript prior to publication."

The Acknowledgements should read:

"This study was supported in part by the JAXA-ISS Space Medicine Program Grant from the Japan Aerospace Exploration Agency. The authors gratefully thank the astronaut who took part in this study, Dr. Satoshi Furukawa and Dr. Shin Yamada of JAXA for their encouragement to complete this study, Dr. Ikuya Nonaka, National Center Hospital for Mental Nervous and Muscular Disorders, who contributed to start up this project, Professor John Tremarco of Kagoshima University for his help and guidance during the preparation of this manuscript.”

(i) Open Access This article is licensed under a Creative Commons Attribution 4.0 International License, which permits use, sharing, adaptation, distribution and reproduction in any medium or format, as long as you give appropriate credit to the original author(s) and the source, provide a link to the Creative Commons license, and indicate if changes were made. The images or other third party material in this article are included in the article's Creative Commons license, unless indicated otherwise in a credit line to the material. If material is not included in the article's Creative Commons license and your intended use is not permitted by statutory regulation or exceeds the permitted use, you will need to obtain permission directly from the copyright holder. To view a copy of this license, visit http://creativecommons.org/licenses/by/4.0/.

(C) The Author(s) 2020 